\title{
Strain rate-dependent compressive deformation behavior of Nd-based bulk metallic glass
}

\author{
L.F. Liu ${ }^{\mathrm{a}}$, L.H. Dai ${ }^{\mathrm{a}, *}$, Y.L. Bai ${ }^{\mathrm{a}}$, B.C. Wei ${ }^{\mathrm{b}}$, G.S. Yu ${ }^{\mathrm{b}}$ \\ ${ }^{a}$ State key Laboratory of Nonlinear Mechanics, Institute of Mechanics, Chinese Academy of Science, Beijing 100080, People's Republic of China \\ ${ }^{\mathrm{b}}$ National Microgravity Laboratory, Institute of Mechanics, Chinese Academy of Science, Beijing 100080, People's Republic of China
}

Received 25 January 2004; accepted 10 January 2005

Available online 2 April 2005

\begin{abstract}
Compressive deformation behavior of the $\mathrm{Nd}_{60} \mathrm{Fe}_{20} \mathrm{Co}_{10} \mathrm{Al}_{10}$ bulk metallic glass was characterized over a wide strain rate range $\left(6.0 \times 10^{-4}\right.$ to $\left.1.0 \times 10^{3} \mathrm{~s}^{-1}\right)$ at room temperature. Fracture stress was found to increase and fracture strain decrease with increasing applied strain rate. Serrated flow and a large number of shear bands were observed at the quasi-static strain rate $\left(6.0 \times 10^{-4} \mathrm{~s}^{-1}\right)$. The results suggest that the appearance of a large number of shear bands is probably associated with flow serration observed during compression; and both shear banding and flow serration are a strain accommodation and stress relaxation process. At dynamic strain rates $\left(1.0 \times 10^{3} \mathrm{~s}^{-1}\right)$, the rate of shear band nucleation is not sufficient to accommodate the applied strain rate and thus causes an early fracture of the test sample. The fracture behavior of the $\mathrm{Nd}_{60} \mathrm{Fe}_{20} \mathrm{Co}_{10} \mathrm{Al}_{10}$ bulk metallic glass is sensitive to strain rate.
\end{abstract}

(C) 2005 Elsevier Ltd. All rights reserved.

Keywords: A. Rare-earth intermetallics; B. Mechanical properties at ambient temperature; B. Glasses, metallic; C. Casting; F. Mechanical testing

\section{Introduction}

Recently, due to the development of bulk metallic glasses (BMGs), intensive efforts have been focused on the preparation and mechanical deformation behaviors of BMG because of the basic science and potential engineering application of the materials [1-14]. This class of materials exhibit many unique mechanical properties, e.g. extremely high strength, fracture toughness, large elastic deformation, shaping and forming in a viscous state, reduced sliding friction and improved wear resistance [15-18].

Understanding the deformation mechanism of BMGs is very important for the application of this class of materials to a variety of engineering problems. The mechanical behaviors of BMGs can be classified by either inhomogeneous or homogeneous deformation. Inhomogeneous deformation usually occurs when a metallic glass is deformed at low temperatures (e.g. room temperature)

\footnotetext{
* Corresponding author. Tel.: +8610 62616852; fax: +86 1062579511. E-mail address: 1hdai@lnm.imech.ac.cn (L.H. Dai).
}

0966-9795/\$ - see front matter (C) 2005 Elsevier Ltd. All rights reserved. doi:10.1016/j.intermet.2005.01.012 and high stress. At high stress, inhomogeneous plastic deformation is usually localized into narrow shear bands. In compression, BMG exhibits essentially no strain hardening, and plastic flow is serrated with many small load drops that correspond to the activation of individual shear bands. Wight et al. [19], Golovin et al. [20] and Schuh et al. [21] studied the serrated flow in BMG using nanoindentation. The result was shown to depend strongly on the indentation strain rate, with lower rates promoting more prominent serrations or displacement bursts.

In contrast to inhomogeneous deformation, homogeneous deformation in BMGs usually takes place at high temperatures $\left(>0.70 T_{\mathrm{g}}\right.$, where $T_{\mathrm{g}}$ is the glass transition temperature), and the materials usually exhibit significant plasticity. This is especially the case in the supercooled liquid region. It has been found that many metallic glasses do not actually exhibit Newtonian behavior in the supercooled liquid region, and in particular this is true at high strain rates. Kawamura et al. [22] and Wei et al. [23] showed that the plastic behavior was strongly dependent on the strain rate. The Newtonian behavior of $\mathrm{Nd}_{60} \mathrm{Fe}_{20} \mathrm{Co}_{10} \mathrm{Al}_{10}$ bulk metallic glass changed to non-Newtonian behavior when the strain rate was increased from $1.4 \times 10^{-4}$ to $1.4 \times 10^{-2} \mathrm{~s}^{-1}$ at $503 \mathrm{~K}$. 
However, the effects of strain rate in BMGs are dependent on the loading conditions and chemical components of the material itself. BMGs with different chemical components usually show different strain rate dependent behaviors. This is especially true at room temperature. Owen et al. [24] found that the dynamic fracture toughness of a $\mathrm{Zr}$ based BMG dramatically increased as loading rates increased at room temperature. Bruck et al. [25] reported that the compressive strength of a $\mathrm{Zr}$ based BMG was independent of the strain rate. Hufnagel et al. [26] observed that the uniaxial compression failure stress decreased with increasing strain rate. Maddin and Masumoto [27] showed that the fracture stress of $\mathrm{Pd}_{80} \mathrm{Si}_{20}$ filament decreased with an increasing strain rate. Kawamura et al. [28] also reported that the tensile strength of a rapidly solidified $\mathrm{Zr}_{65} \mathrm{Al}_{10} \mathrm{Ni}_{10} \mathrm{Cu}_{15}$ ribbon specimen decreased with an increasing strain rate. Apparently, the strain rate dependence of deformation behaviors in amorphous alloys varies with material composition, specimen shape and loading procedure.

Bulk metallic glasses obtained in multicomponent (Nd,Pr)-Fe based systems with hard magnetic properties at room temperature have been reported recently [29-31]. These systems have no distinct glass transition prior to crystallization according to the constant-rate heating DSC measurements, indicating a low thermal stability of the supercooled liquid. However, an extremely high ratio between the $T_{\mathrm{x}}$ (crystallization temperature) and $T_{1}$ (liquid temperature), around 0.9, was observed for such systems, which indicates a rather high stability of amorphous phase against crystallization. The contradiction between the absence of a marked glass transition and the extremely high value of $T_{\mathrm{x}} / T_{1}$ shows that these systems are rather unique within the different families of BMGs.

To date, no data is currently available on dynamic constitutive behavior for this class of BMGs. However, the characterization of dynamic constitutive behavior of this material is very important for its potential engineering applications. The objective of this paper is to investigate the effect of the strain rate on the compressive behavior of the $\mathrm{Nd}_{60} \mathrm{Fe}_{20} \mathrm{Co}_{10} \mathrm{Al}_{10}$ BMG at room temperature. The results redound to comprehend the fracture mechanism and predict the failure behaviors in engineering application.

\section{Material prepared and characterized}

Pre-alloyed $\mathrm{Nd}_{60} \mathrm{Fe}_{20} \mathrm{Co}_{10} \mathrm{Al}_{10}$ ingots were prepared by arc-melting a mixture of $\mathrm{Nd}, \mathrm{Fe}, \mathrm{Co}$, and $\mathrm{Al}$ elements with a purity of at least $99.9 \%$ in a titanium-gettered argon atmosphere. Cylindrical specimens of $5 \mathrm{~mm}$ in diameter and $70 \mathrm{~mm}$ in length were prepared from the pre-alloyed ingots by suction casting into a copper mold. The structure of the cast cylinders was characterized by X-ray diffraction (XRD) in a Philip PW 1050 diffractometer using Co $\mathrm{K}_{\alpha}$ radiation. Fig. 1 is an XRD spectrum of the as-cast cylinder

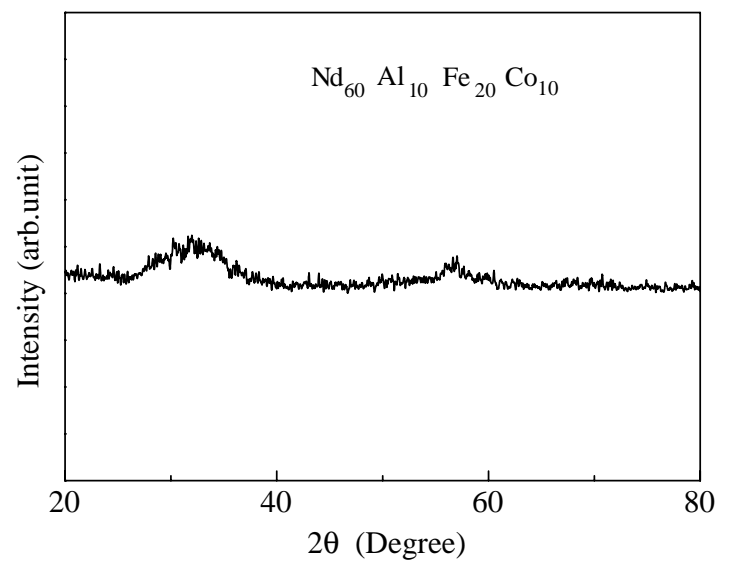

Fig. 1. X-ray diffraction pattern taken from as-cast $\mathrm{Nd}_{60} \mathrm{Fe}_{20} \mathrm{Co}_{10} \mathrm{Al}_{10}$ BMG.

alloy. The XRD spectrum showed that the alloy is a typical amorphous one without obvious crystalline reflection peaks.

\section{Experimental procedure}

To study the compressive behavior of $\mathrm{Nd}_{60} \mathrm{Fe}_{20} \mathrm{Co}_{10} \mathrm{Al}_{10}$ over a wide range of strain rates at room temperature, both dynamic and static compression tests were carried out. At both dynamic and static compression tests, more than 12 specimens were tested for investigation.

The dynamic compression tests at a strain rate about $1 \times 10^{3} \mathrm{~s}^{-1}$ were performed with a split-Hopkinson pressure bar (SHPB) apparatus. A high strength steel was used for the striker, input, output and unloading bars with a diameter of $13 \mathrm{~mm}$. The schematic diagram of SHPB is shown in Fig. 2. As the input bar was struck, a compressive impulse was generated and propagated through the input bar and loaded the sample. At the interface, part of the compressive wave reflected back to the input bar and the remaining energy was transmitted into the output bar and the unloading bar. In accordance with the elastic properties of the bars and the recorded wave profiles, the dynamic compression stress-strain state in the sample can be measured.

The incident, reflected and transmitted pulses were measured by two sets of $180^{\circ}$ symmetrical strain gages mounted on the input and output bars, respectively. The signals from the input and output bars were conducted to dynamic strain amplifiers and a digital oscilloscope. These two instruments were used for data acquisition. Therefore, the average strain rate, the strain and the stress can be calculated according to the incident wave $\varepsilon_{\mathrm{i}}(t)$; the reflected wave, $\varepsilon_{\mathrm{r}}(t)$, measured by the gages on the input bar; and the transmitted wave $\varepsilon_{\mathrm{t}}(t)$ measured by the gages on the output bar as follows

$\dot{\varepsilon}=-\frac{2 C_{\mathrm{b}}}{L_{\mathrm{s}}} \varepsilon_{\mathrm{r}}(t)$ 


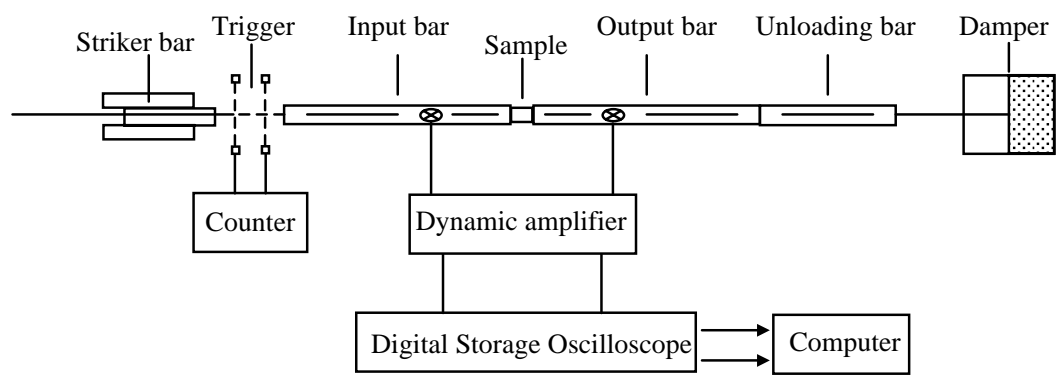

Fig. 2. Schematic diagram of split Hopkinson bar and recording system.

$\varepsilon=-\frac{2 C_{\mathrm{b}}}{L_{\mathrm{s}}} \int_{0}^{t} \varepsilon_{\mathrm{r}}(t) \mathrm{d} t$

$\sigma=\frac{A_{\mathrm{b}} E_{\mathrm{b}}}{A_{\mathrm{s}}} \varepsilon_{\mathrm{r}}(t)$

where $A, L, E, C$ are the cross section area, the length, the elastic modulus and the elastic wave velocity, respectively. $\mathrm{s}$ and $\mathrm{b}$ refer to the specimen and the pressure bar, respectively.

The quasi-static compression tests were performed with an MTS-810 machine on cylindrical samples, $5 \mathrm{~mm}$ in diameter and $10 \mathrm{~mm}$ in length, at room temperature. Two strain rates were used, $6.0 \times 10^{-4}$ and $6.0 \times 10^{-2} \mathrm{~s}^{-1}$. The surfaces of tested samples were examined using scanning electron microscopy (SEM).

\section{Results and discussion}

Compression stress-strain curves of the present bulk metallic glass $\mathrm{Nd}_{60} \mathrm{Fe}_{20} \mathrm{Co}_{10} \mathrm{Al}_{10}$ are shown in Fig. 3 for different strain rates. The curves demonstrate that the material exhibits the maximum fracture stress of about $430 \mathrm{MPa}$ at a dynamic strain rate of $1.0 \times 10^{3} \mathrm{~s}^{-1}$ and about $360 \mathrm{MPa}$ at a quasi-static strain rate of $6.0 \times 10^{-4} \mathrm{~s}^{-1}$. At quasi-static loading conditions, the flow is noted to be serrated, this is similar to that observed previously in Zr-based [32] and Pd-based [33] BMGs. Also, serrated flow has been proposed to be associated with the emission of localized shear bands [32].

It is of interest to note that the amplitude of the serrated flow decreases with increasing strain rate; this is similar to the report of Mukai et al. [34] on the $\mathrm{Pd}_{40} \mathrm{Ni}_{40 \mathrm{P}_{20}} \mathrm{BMG}$. Actually, flow serration gradually diminishes at the strain rate of $1.0 \times 10^{3} \mathrm{~s}^{-1}$. Another obvious observation is that the fracture stress increases with the increasing strain rate. However, the fracture strain decreases with the increasing strain rate.

It is known that the strength of crystalline alloys is strongly dependent on the activities of dislocations and that dislocation interactions are stronger at high strain rates. For example, polycrystalline metals and crystalline alloys with FCC [35,36], BCC [37], and HCP [38] structures normally exhibit a higher strength at dynamic strain rates than that at quasi-static strain rates. In the case of metallic glasses, localized shear band formation is the dominant deformation mode at room temperature. As shown in the flow serration of stress strain curves, during the quasi-static deformation, more serrated flow means more localized shear bands are formed in the sample than that during dynamic deformation. This was verified by the later observations of the crosssectioned sample, slice perpendicular to the catastrophic shearing fracture surface. Furthermore, the fact that the fracture strain at quasi-static strain rates are larger than that at dynamic strain rates demonstrated that the formation of shear bands can accommodate the applied strain and thus causes an earlier fracture of the sample at dynamic strain rates than that at quasi-static strain rates. Thereby, deformation at dynamic strain rates are prone to focusing on a major shear band and the fracture stress reflects the true failure behavior of this material without the influences of a large number of localized shear bands. In this way, the material is designed to fracture with little fracture strain at dynamic strain rates. At quasi-static strain rates,

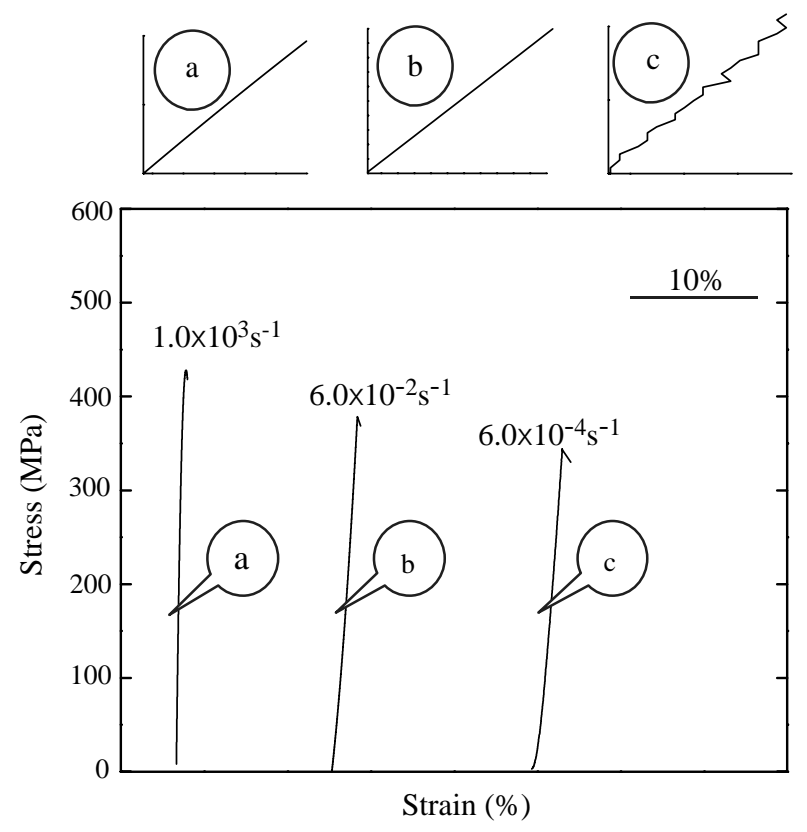

Fig. 3. Compression stress-strain curves of $\mathrm{Nd}_{60} \mathrm{Fe}_{20} \mathrm{Co}_{10} \mathrm{Al}_{10} \mathrm{BMG}$ at different strain rates. 


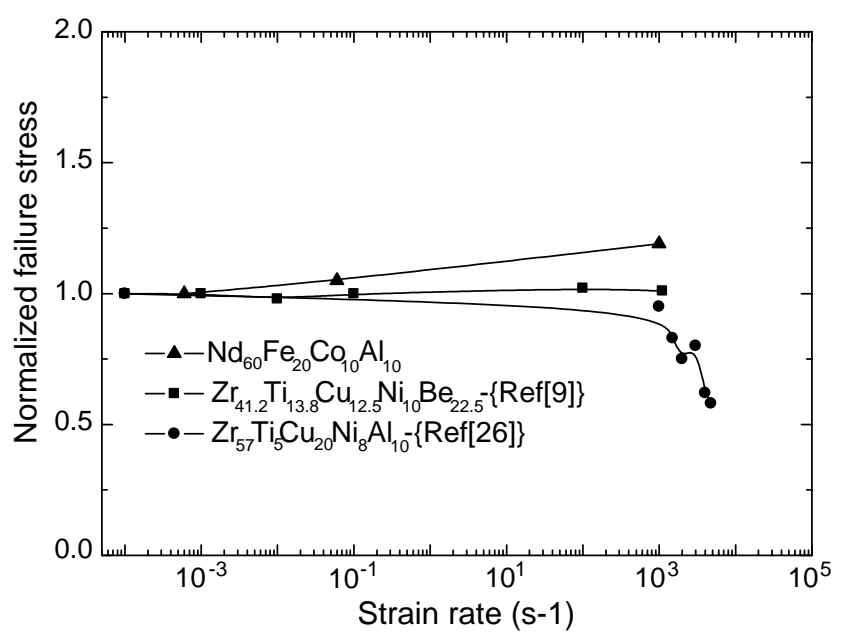

Fig. 4. Dependence of failure stress (normalized by the failure stress under quasi-static loading) on the strain rate for three bulk metallic glasses.

the localized shear bands accommodate the applied strain and the fracture stress is lower than that at dynamic strain rates. Thereby, the deformation behavior of this material manifests strain rate dependency.

The present experimental result that the failure stress increases with increasing strain rate is in contrast to Hufnagel et al.'s experimental observation for a Zr-based BMG [26]. This difference demonstrates that BMGs deform by a shear banding mechanism is material-related [4]. As is illustrated in Fig. 4, BMGs with different chemical components manifest different strain rate effect. Bruck et al. [25] and $\mathrm{Lu}$ et al. [9] reported that the compressive strength of a $\mathrm{Zr}$ based BMG was independent of the strain rate. Hufnagel et al. [26] observed that the uniaxial compression failure stress decreased with increasing strain rate. The material-related mechanism of shear banding in BMGs may be contributed to the microstructure difference in different materials with different chemical components, e.g. cluster structure. Simultaneity, as demonstrated in Liu et al. [4] and Hufnagel et al.'s discussions [26], adiabatic heating plays an important role in the deformation by a shear banding. The effect of adiabatic heating in the deformation of BMGs also makes the BMGs deform by a shear banding mechanism is material-related because materials with different chemical components have different physical properties, e.g. heat softening.

Fracture samples were examined to understand the deformation behavior of the present $\mathrm{Nd}_{60} \mathrm{Fe}_{20} \mathrm{Co}_{10} \mathrm{Al}_{10}$ bulk metallic glass at different strain rates. It is interesting to note that catastrophic failure of dynamic compression samples occurred due to shear banding along a plane oriented $\sim 42^{\circ}$ to the loading axis as seen in Fig. 5(a), while the quasi-static compression samples fractured at $\sim 40^{\circ}$ (Fig. 5(b)). The fact that the dynamic compression sample was sheared off at $\sim 42^{\circ}$ with respect to the loading axis also agrees with those observed during compression of Zr-based [39] and Pd-based BMGs [40]. However, the quasi-static compression sample of this material fractured at $\sim 40^{\circ}$ with respect to the loading axis, this is different from other BMGs. This difference demonstrates that, in this class of BMGs, the inclination angle of the fracture plane is slightly dependent on the strain rate for the present study. In the analysis below, we will find that multiple shear bands, formed in the quasi-static compression tests, may be responsible for the difference.

From the above observations, it was found that the compressive fracture angle is approximately $40-42^{\circ}$, i.e. smaller than $45^{\circ}$. The result that the compressive fracture does not occur along the plane of maximum shear stress demonstrates that yielding in Nd-based BMGs follows a Mohr-Coulomb criterion, rather than the von Mises criterion, which is appropriate to polycrystalline metals. According to Mohr-Coulomb model, the normal
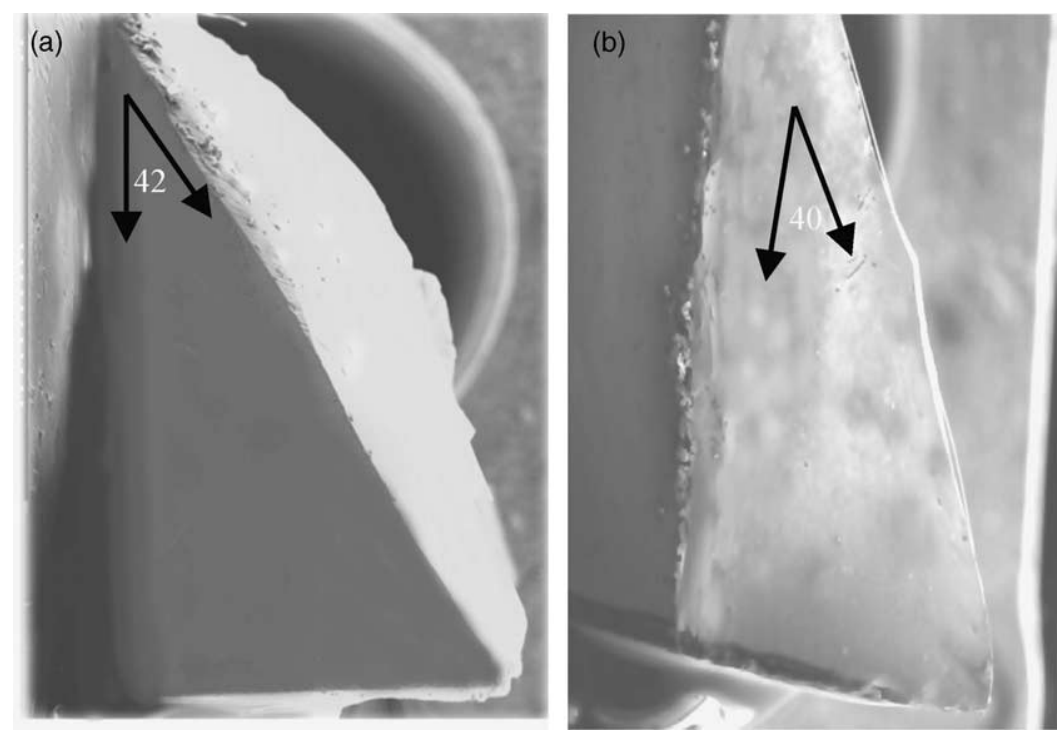

Fig. 5. SEM graphs of shear failure surfaces of BMG fractured by uniaxial compression at $293 \mathrm{~K}$ : (a) dynamic strain rate; (b) quasi-static strain rate. 
(a)

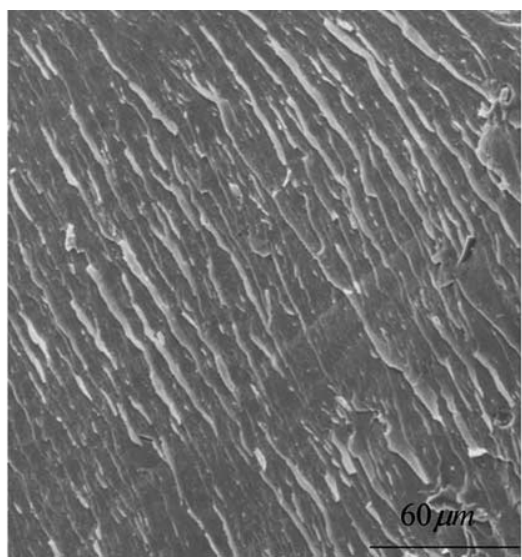

(b)

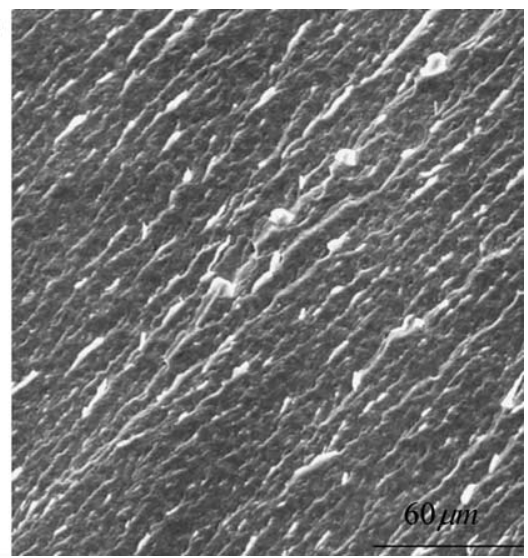

Fig. 6. Vein pattern morphology on fracture surface of $\mathrm{Nd}_{60} \mathrm{Fe}_{20} \mathrm{Co}_{10} \mathrm{Al}_{10} \mathrm{BMG}$ : (a) thick vein pattern at quasi-static strain rate; (b) vein pattern with melting drops.

stress-dependent effective shear stress on the fracture plane can be written as $[40,41]$

$\tau_{\mathrm{e}}=\tau+\alpha \sigma_{\mathrm{n}}$

and the Mohr-Coulomb yield criterion can be expressed as

$\tau_{\mathrm{e}}=k_{0}$

where $\tau$ is the shear stress on the fracture plane, $k_{0}$ and $\alpha$ are constants, and $\sigma_{\mathrm{n}}$ is the stress component in the direction normal to the fracture plane. When the sample is subject to uniaxial compressive stress $-\sigma(\sigma>0)$, Eq. (5) can be rewritten as

$\tau_{\mathrm{e}}=\sigma \sin \theta \cos \theta-\alpha \sigma \sin ^{2} \theta=k_{0}$

Where $\theta$ is the angle between the fracture plane and the loading axis. Taking the derivative of $\tau_{\mathrm{e}}$ with respect to $\theta$ gives

$\frac{\partial \tau_{\mathrm{e}}}{\partial \theta}=\sigma(\cos 2 \theta-\alpha \sin 2 \theta)$

The minimum effective loading stress $\tau_{\mathrm{e}}$ is obtained when

$\frac{\partial \tau_{\mathrm{e}}}{\partial \theta}=\sigma(\cos 2 \theta-\alpha \sin 2 \theta)=0$

If $\alpha=0.105$ and $0.176, \theta=42$ and 40 are predicted, respectively. Due to the absence of strain hardening, the sample is expected to experience deformation localization immediately after the initial yielding along the sheared off plane [42].

Details of fracture surfaces of deformed samples at strain rates of $6.0 \times 10^{-4}$ and $1.0 \times 10^{3} \mathrm{~s}^{-1}$ are shown in Fig. 6(a) and (b), respectively. In the case of deforming at quasi-static strain rates, wide, flat and elongated veins extend along the shear surface from the edge of a shear step of the sample surface. The veins are thicker than that observed at dynamic strain rates (Fig. 6(b)). As shown in Fig. 7, parallel to the catastrophic shearing fracture surface, many shear bands are observed. For the quasi-static case, the appearance of a large number of shear bands is probably associated with flow serration observed during compression (Fig. 3) and is thus responsible for a decrease in the fracture stress. These results suggest that flow serration is a strain accommodation or stress relaxation process. At this dynamic strain rate, the nucleation rate of shear bands is not sufficient to accommodate the applied strain rate and thus causes an early fracture of the test sample.

The scanning electron micrographs in Fig. 6 indicate that the failure surface of samples deformed at dynamic strain rates have quite a different appearance, which can be seen in Fig. 6(b). The only morphologies that are evident on the failure surface are vein-like patterns and the localized melting drops. These features are similar to those observed on the failure surfaces of other metallic glass samples tested in dynamic compression. An explanation for these features has been proposed which asserts that the viscosity of the material within the shear band is reduced considerably because of adiabatic heating generated by the enormous

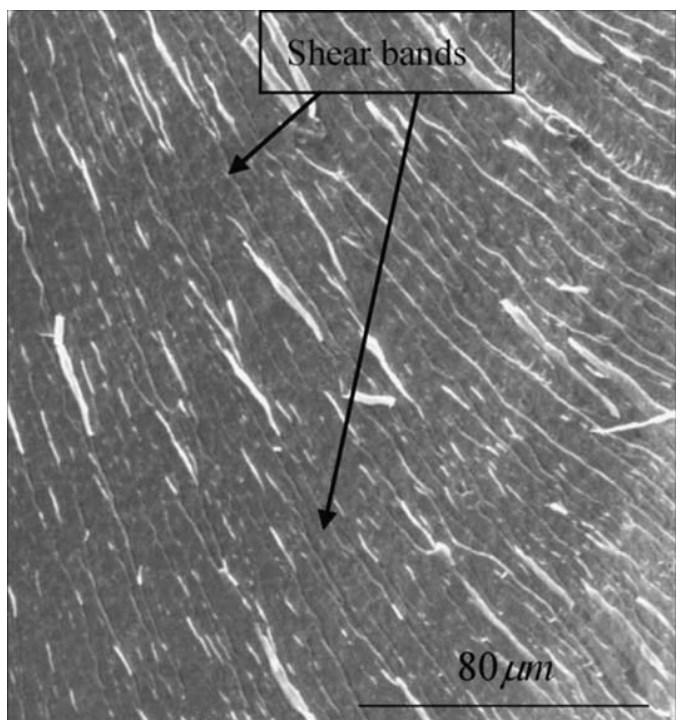

Fig. 7. Shear band structure parallel to the catastrophic fracture surface at quasi-static strain rate. 
plastic deformation within the shear band, which preceded catastrophic failure [43]. As the material separates, pores are opened up, leaving behind the vein-like morphology. This hypothesis has been confirmed by shear experiments performed on a viscous material that has been placed between glass slides [44]. After the slides are sheared apart, a vein-like morphology is revealed on the separated surfaces.

\section{Conclusions}

The compressive deformation behavior of $\mathrm{Nd}_{60} \mathrm{Fe}_{20}$ $\mathrm{Co}_{10} \mathrm{Al}_{10}$ was characterized over a wide strain rate range $\left(6.0 \times 10^{-4}\right.$ to $\left.1.0 \times 10^{3} \mathrm{~s}^{-1}\right)$ at room temperature. Serrated flow is observed in the stress-strain curves of quasi-static strain rates $\left(6.0 \times 10^{-4} \mathrm{~s}^{-1}\right)$, but diminishes at dynamic strain rates $\left(1.0 \times 10^{3} \mathrm{~s}^{-1}\right)$. The large numbers of shear bands are probably associated with flow serration observed during compression, and are responsible for the decrease in fracture stress. The results suggest that shear banding and flow serrations are a strain accommodation and stress relaxation mechanism for deformation. At dynamic strain rates $\left(1.0 \times 10^{3} \mathrm{~s}^{-1}\right)$, the nucleation rate of shear bands are not sufficient to accommodate the applied strain rate and thus cause an early fracture of the test sample. The fracture behavior of the $\mathrm{Nd}_{60} \mathrm{Fe}_{20} \mathrm{Co}_{10} \mathrm{Al}_{10}$ bulk metallic glass is sensitive to strain rate.

\section{Acknowledgements}

The authors gratefully acknowledge the financial support of this work by the National Natural Science Foundation of China through projects of 10472119 and 10232040.

\section{References}

[1] Chen HS. Rep Prog Phys 1980;43:353.

[2] Inoue A, Zhang T, Masumoto T. Mater Trans, JIM 1990;31:425.

[3] Johnson WL. MRS Bull 1999;24:42.

[4] Liu CT, Heatherly L, Easton DS, Carmichael CA, Schneibel JH, Chen HS, et al. Metall Mater Trans A 1998;29:1811.

[5] Lu ZP, Liu CT. Acta Mater 2002;50:3501.

[6] Flores KM, Dauskardt RH. Scripta Mater 1999;41:937.

[7] Loffler JF. Intermetallics 2003;11:529.
[8] Nieh TG, Wadsworth J, Liu CT, Ohkubo T, Hirotsu Y. Acta Mater 2001;49:2887.

[9] Lu J, Ravichandran G, Johnson WL. Acta Mater 2003;51:3249.

[10] Zhang QS, Guo DY, Wang AM, Zhang HF, Ding BZ, Hu ZQ. Intermetallics 2002;10:1197.

[11] Wang YL, Xua J, Yang R. Mater Sci Eng A 2003;352:112.

[12] Wang WH, Wang RJ, Dai DY, Zhao DQ, Pan MX, Yao YS. Appl Phys Lett 2001;8:1108.

[13] Hui XD, Kou HC, He JP, Wang YL, Dong W, Chen GL. Intermetallics 2002;10:1065.

[14] Zhang ZF, Eckert J, Schultz L. Acta Mater. 2003;51:1167.

[15] Hays CC, Kim CP, Johnson WL. Phys Rev Lett 2000;84:2901.

[16] Kawamura Y, Shibata T, Inoue A, Masumoto T. Appl Phys Lett 1996; 69:1208.

[17] Wang JG, Choi BW, Nieh TG, Liu CT. J Mater Res 2000;15:913.

[18] Li JX, Shan GB, Gao KW, Qiao LJ, Chu WY. Mater Sci Eng A 2003; 354:337.

[19] Wight WJ, Saha R, Nix WD. Mater Trans, JIM 2001;42:642.

[20] Golovin YI, Ivolgin VI, Khonik VA, Kitagawa K, Tyurin AI. Scripta Mater 2001;45:947.

[21] Schuh F, Nieh TG, Kawamura Y. J Mater Res 2002;17:1651.

[22] Kawamura Y, Nakamura T, Inoue A. Scripta Mater 1998;39:301.

[23] Wei BC, Löser W, Xia L, Roth S, Wang WH, Eckert J. Acta Mater 2002;50:4357.

[24] Owen DM, Rosakis AJ, Johnson WL. In: Inoue A, Liu CT, editors. MRS symposium proceedings, vol. 554, 1999. p. 419.

[25] Bruck HA, Rosakis AJ, Johnson WL. J Mater Res 1996;11:503.

[26] Hufnagel TC, Jiao T, Li Y, Xing LQ, Ramesh KT. J Mater Res 2002; 17:1441.

[27] Maddin R, Masumoto T. Mater Sci Eng 1972;9:153.

[28] Kawamura Y, Shibata T, Inoue A, Masumoto T. Scripta Mater 1997; 37:431.

[29] Inoue A, Zhang T, Takeuchi A, Zhang W. Mater Trans, JIM 1996;37: 636.

[30] Chiriac H, Lupu N. J Non-Cryst Solids 2001;287:135.

[31] Qiu KQ, Zhang HF, Wang AM, Ding BZ, Hu ZQ. Acta Mater 2002; 50:3567.

[32] Wight WJ, Schwarz RB, Nix WD. Mater Sci Eng A 2001;319-321: 229.

[33] Kimura H, Masumoto T. Acta Metall 1983;31:231.

[34] Mukai T, Nieh TG, Kawamura Y, Inoue A, Higashi K. Intermetallics 2002;10:1071.

[35] Lindholm US, Yeakley LM. Exp Mech 1967;7:1.

[36] Follansbee PS, Kocks UF. Acta Metall 1988;36:81.

[37] Schulze V, Vohringer O. Metall Mater Trans A 2000;31A:825.

[38] Follansbee PS, Gray GT. Metall Trans A 1989;20A:863.

[39] Wright WL, Nix WD. Mater Trans, JIM 2001;42:642.

[40] Donovan PE. Acta Metall 1989;37:445.

[41] Vaidyanathan R, Dao M, Ravichandran G, Suresh S. Acta Mater 2001;49:3781.

[42] Asaro RJ, Jukes JA. J Mech Phys Solids 1977;25:309.

[43] Leamy HJ, Chen HS, Wang TT. Metall Trans 1972;3:699.

[44] Pampillo CA, Reimschuessel AC. J Mater Sci 1974;9:718. 